\title{
O AFETO E A REFLEXÃO
}

Sylvain Tousseul

Encarregado

de cursos de

epistemologia e

psicopatologia

clínica na

Universidade de

Paris 7 Denis-

Diderot. Pesquisador

em psicopatologia

clínica no Centre

de Recherche

Psychanalyse

Médecine et Société.

Encarregado de

RESUMO: Inspirando-se na metapsicologia freudiana e na filosofia de Leibniz, este artigo mostra que as dinâmicas afetivas é que animam as lógicas reflexivas. A primeira dinâmica afetiva consiste em incluir representações para substituir as que foram recalcadas, o que constitui a lógica da equivalência do princípio de identidade. Quanto à segunda dinâmica afetiva, consiste em compensar frustrações encontrando os recursos que sejam suficientes para sublimá-las, o que constitui a lógica indutiva do princípio de razão suficiente. cursos em Filosofia na École Supérieure de Commerce de Rouen.

Pesquisador em filosofia no Centre de Recherche Philosophie et Esthétique na Universidade Paris 10-Nanterre. Psicólogo clínico em hospital-dia no Institut Paul Sivadon em Paris.

Tradução

Pedro Henrique Bernardes Rondon Dito de outra maneira, a reflexão é a simples expressão linguageira de determinados afetos.

Palavras-chave: Afeto, reflexão, lógica, linguagem, Freud, Leibniz.

ABSTRACT: The affection and the reflection. Notably being inspired by the Freudian metapsychology and the Leibnizian philosophy, this article defines that reflexive logics are stimulated by affective dynamics. The first affective dynamic consists in connecting affects to representations using a set of identifications, which constitutes the equivalence logic of the identity principle. The second affective dynamic consists in compensating frustrations by finding sufficient means for sublimating them; this constitutes the inductive logic of the principle of sufficient reason. In other words, reflection is just the linguistic expression of some affects.

Keywords: Affect, reflection, logic, language, Freud, Leibniz. 


\section{INTRODUÇÃO}

A tradição filosófica algumas vezes opõe o afeto à reflexão, condenando o primeiro sob o pretexto de que prejudica a segunda, como fica evidenciado pelo ideal apático de Kant (KANT, 1798/2002, § 81, p.196). Conjugando a psicanálise e a filosofia, queremos demonstrar que, ao contrário, as dinâmicas afetivas animam as lógicas reflexivas porque, em certo sentido, o corpo impele o espírito a refletir em função do espaço e do tempo nos quais ele se encontra. Para demonstrar isso, vamos de início elaborar uma hipótese epistemológica com a qual é possível explicar a eventual reflexividade dos afetos, o que nos permitirá em seguida pôr à prova sua pertinência perguntando-nos como o espaço e o tempo nos impelem a refletir.

\section{A HIPÓTESE EPISTEMOLÓGICA DOS AFETOS REFLEXIVOS}

\section{A legitimidade das lógicas clássicas}

Como lembra Largeault (1993/1998, p.110), existem quatro lógicas clássicas. Os filósofos e os lógicos as denominam dessa maneira porque elas constituem as lógicas essenciais das quais decorrem as demais. Algumas vezes são qualificadas como fundamentais porque fundamentam as outras sem, todavia, se reduzir a isso, da mesma maneira que elas não podem se reduzir entre si. Essas quatro lógicas constituem, portanto, o fundamento de todos os nossos raciocínios e de todas as nossas reflexões. Não estão reservadas apenas aos sábios, cientistas ou matemáticos, uma vez que nós todos as utilizamos no dia a dia por ocasião de tarefas comuns, como verificar que uma porta esteja bem fechada, entregar o dinheiro, ou utilizar um guarda-chuva porque está chovendo, ou ainda e simplesmente ao reconhecer alguém na rua. Cada uma dessas tarefas implica, de fato, uma lógica clássica diferente. Por exemplo, verificar que a porta esteja bem fechada corresponde à lógica bivalente que consiste em distinguir o verdadeiro do falso; entregar o dinheiro corresponde à lógica dedutiva que permite deduzir o que deve ser pago em relação àquilo que foi dado; utilizar o guarda-chuva corresponde à lógica indutiva que permite encontrar uma razão que seja suficiente para se proteger da chuva, e reconhecer alguém como idêntico à pessoa que encontramos antes. É possível constatar, com esses exemplos, a importância que as quatro lógicas clássicas adquirem na vida de cada pessoa, mas também no campo do conhecimento e dos saberes, uma vez que qualquer teoria as pressupõe, ao menos de modo implícito.

Por muito tempo elas permaneceram sem prova, em especial porque parecem de tal maneira evidentes que os sábios nunca descobriram justificação para elas. Aliás, o próprio Aristóteles (1991, t.I, 1.IV, Ch.4, 1006a5-15, p.123), que foi o primeiro a pôr em destaque essas quatro lógicas analisando o discurso, avaliava 
que elas não precisavam ser demonstradas, uma vez que são elas que permitem elaborar qualquer demonstração.

Essas considerações aristotélicas se revelaram bastante premonitórias uma vez que 2.5000 anos mais tarde, Gödel (1931, p.173-198) encerrava essa busca de demonstrações estabelecendo dois teoremas segundo os quais sempre restará uma lógica injustificada, quaisquer que sejam as outras que utilizemos para fazer a demonstração. As lógicas clássicas, portanto, são indemonstráveis. É por isso que tivemos a ideia de justificar essas quatro lógicas apoiando-nos na experiência, e não mais na demonstração como os sábios tinham tentado fazer até o presente. Mostramos assim em trabalhos recentes (TOUSSEL, 2006) que cada uma dessas quatro lógicas consistia em afastar uma experiência que era impossível de realizar, seja por razões espaciais, seja por razões temporais.

Consideremos, por exemplo, as duas lógicas reflexivas. A lógica de equivalência repousa sobre o princípio de identidade que consiste em estabelecer o fato de que uma coisa é idêntica a outra ou a ela mesma. Ora, essas equivalências só são possíveis porque não podemos estar em toda parte, em todos os lugares. Se, por exemplo, nos encontrarmos num lugar observando uma coisa e, ao nos deslocarmos para outro lugar encontramos a mesma coisa, isso significa que é a mesma coisa que também se deslocou, ou então que se trata de uma outra que lhe é idêntica. Nos dois casos, é porque não podemos fazer a experiência de ubiquidade que podemos estabelecer equivalências entre diversas coisas, ou que podemos reconhecer uma coisa como idêntica a ela mesma.

É, portanto, porque é impossível fazer a experiência da ubiquidade que refletimos segundo uma lógica de equivalência. Da mesma maneira, a lógica de indução se baseia no princípio de razão suficiente que consiste em estabelecer o fato de que basta uma coisa para engendrar outra. E se podemos inferir uma coisa a partir de outra, é apenas porque não podemos fazer a experiência da eternidade. De fato, o tempo de observação de uma coisa não pode durar eternamente, de modo que se quisermos fixar nosso estado a um momento dado, estaremos obrigados a distinguir as razões que bastam para conduzir a isso. É, portanto, por ser impossível fazer a experiência da eternidade que refletimos de acordo com a lógica indutiva do princípio de razão suficiente.

Nossos trabalhos anteriores permitiram legitimar as lógicas clássicas mostrando que elas consistiam em afastar experiências espaçotemporais impossíveis de realizar. Como, porém, explicar que os afetos intervêm em nossas reflexões?

\section{Como os afetos intervêm nas nossas reflexões?}

Neste estádio de nossas pesquisas, poderíamos ter ficado satisfeitos de ter estabelecido a legitimidade das lógicas. Entretanto, um problema fundamental ainda subsistia: o dos afetos. De fato, se a tradição filosófica muitas vezes opõe 
os afetos à reflexão, é porque presume que eles atrapalhem nossa maneira de refletir. No entanto, em seguida à leitura de determinado número de trabalhos ${ }^{1}$ nós, ao contrário, ficamos convencidos de que os afetos eram necessários à reflexão. Mas como explicar isso?

Em primeiro lugar convém observar que a maior parte do tempo não estamos conscientes de refletir segundo lógicas empíricas, e quando temos vontade de fazer isso seguindo uma reflexão lógica, é apenas para tentar não incorrer em enganos. É, portanto, muito provável que seja nosso inconsciente que nos faz refletir logicamente. E como é a psicanálise que estuda o inconsciente, somos obrigados a acioná-la para compreender como os afetos poderiam intervir em nossas reflexões, o que foi uma orientação das mais heurísticas, tão eloquente é a aproximação de nossos trabalhos da metapsicologia freudiana.

De fato, por um lado a clínica mostra que quando não é possível realizar uma pulsão, quatro destinos pulsionais são possíveis. Ora, nossos trabalhos mostram da mesma maneira que quando não é possível realizar uma experiência, quatro lógicas são possíveis. Por outro lado, uma pulsão se compõe de um afeto, que dá a forma à pulsão, e de uma representação que lhe dá o conteúdo. Ora uma reflexão se compõe da mesma maneira, com uma lógica que dá a forma à reflexão, e um discurso que lhe dá o conteúdo.

Todas essas semelhanças concorrem para nos fazer pensar que as quatro impossibilidades espaçotemporais da experiência engendram cada destino pulsional cuja dinâmica afetiva constitui o motor das quatro lógicas - ao menos, tal é a hipótese que vamos agora tentar demonstrar. Num artigo precedente (TOUSSEUL, 2009) desenvolvemos esta hipótese, considerando apenas as duas lógicas racionais; vamos, daqui por diante, desenvolvê-la considerando somente as duas lógicas reflexivas, isto é, vamos tentar compreender como o espaço e o tempo nos impelem a refletir.

\section{COMO O ESPAÇO NOS IMPELE A REFLETIR?}

\section{Como o espaço afeta nossas representações de objetos?}

Não se pode estar ao mesmo tempo em toda parte, isto é, há objetos que não podem ser experienciados porque estão inacessíveis. Do mesmo modo, há objetos que não podem ser experienciados porque estão interditados pelos costumes da sociedade na qual nos encontramos, como o homicídio ou o incesto, em especial. Dito de outro modo, há um grande número de objetos que

\footnotetext{
${ }^{1}$ Citamos por exemplo: Damasio A. R. (1994/2001), L'erreur de Descartes, trad. M. Blanc. Paris: Odile Jacob; Vincent J. D. (1986/1999), Biologie des passions. Paris: Odile Jacob; Changeux J. P. (1994/2002), Raison et plaisir. Paris: Odile Jacob.
} 
não conhecemos, e para os quais não se pode falar de representação, uma vez que para ter uma re-presentação é necessário já ter tido uma apresentação do objeto. Ora, se não conhecemos o objeto, é muito provável que ele jamais nos tenha sido apresentado, tanto que não podemos fazer dele uma representação. Entretanto, poderiam objetar que é possível ter representações de objetos proibidos ou inacessíveis, por exemplo, olhando a televisão, como os homicídios ou a descrição do planeta Marte, sem por isso ter feito a experiência por nós mesmos. Na realidade, não se trata de re-presentação, mas antes de fantasias, no sentido de que as representações são imagens realmente vividas, ao passo que as fantasias são apenas psíquicas, como explicava Freud (1911/2005, p.20). Assim, os objetos que não conhecemos são fantasiados e suscitam encenações porque não podemos experienciá-los.

E o fato de que há objetos que não podemos experienciar marca os limites do nosso espaço, talvez mesmo o reduza, de modo que quanto mais cercados de objetos desconhecidos, tanto mais nosso espaço se estreita. Esse estado no qual o espaço se reduz não é senão aquilo que é chamado angústia, cuja etimologia latina angustia designa um espaço que se estreita. Não é, portanto, a ausência do objeto que provoca angústia, mas ao contrário, é a presença daqueles que nos são estrangeiros, como observa Assoun (2006, p.81). Encontrar-se, por exemplo, numa festa à noite onde não se conhece ninguém, é angustiante, e essa situação será tanto mais angustiante se o local é vasto e está apinhado. A angústia, portanto, não tem que ser sempre posta em correlação com um espaço estreito, mas antes com a presença de objetos desconhecidos, ou proibidos, ou ainda desagradáveis.

Assim, a angústia se desencadeia em presença de objetos que não experienciamos, ou de obetos proibidos, ou ainda de objetos dos quais temos uma experiência desagradável, e que não desejamos reviver, nem mesmo representar para nós mesmos. Em todos os casos, seja a imagem do objeto uma fantasia ou uma representação, vai ser voluntariamente afastada da consciência uma vez que o objeto está inacessível. Dizemos então que o objeto pulsional está recalcado (FREUD, 1915/2002, p.47), e se torna então inconsciente. Por isso, o inconsciente não é constituído só por representações das quais não temos consciência, mas também por aquelas das quais não queremos ter consciência.

Há, assim, dois tipos de inconsciente: aquele que se compõe daquilo que não conhecemos, como as lógicas que seguimos embora as ignoremos, e aquele que se compõe daquilo que não queremos conhecer, como determinadas fantasias, notadamente sexuais. O recalcamento depende apenas do segundo tipo de inconsciente, e se desencadeia em seguida à presença de um objeto angustiante, aquilo que algumas vezes Freud chama de "angústia-sinal” (FREUD, 1926/2002, p.8). 
A representação ou a fantasia do objeto pulsional é, portanto afastada da consciência, mas e quanto ao afeto que lhe estava ligado? De fato, à medida que o afeto corresponde à energia da pulsão e que a representação do objeto sobre o qual teria podido se escoar, está recalcada, podemos interrogar-nos quanto ao que é feito dessa energia pulsional. De fato, como não pode ser ignorado, o afeto vai ser reinvestido em outras representações conhecidas, autorizadas, ou ainda agradáveis, isto é, que a dinâmica afetiva do "recalcamento é uma transferência de energia” (LE GUEN, 1992/1997, p.14) pulsional para outras fantasias que não aquelas visadas de início. A dinâmica afetiva do recalcamento consiste, portanto, em incluir novas representações ou novas fantasias.

Por conseguinte, quando desejamos um objeto que está inacessível, é proibido ou é desagradável, sua fantasia ou sua representação se tornam angustiantes ao ponto de ser recalcadas. A angústia é, portanto, o afeto a partir do qual o destino pulsional do recalcamento é desencadeado (FREUD, 1926/2002, p.24). E uma vez que a fantasia ou representação do objeto inicialmente desejado está recalcada, o afeto a ele ligado é reinvestido numa fantasia substituta, ou numa outra representação autorizada e agradável; de tal maneira que a dinâmica afetiva do recalcamento é a inclusão. Eis aí como o espaço nos afeta pela presença de objetos desconhecidos, ou proibidos, ou ainda, desagradáveis... mas como será que esse processo psíquico pode constituir um dos motores de nossa reflexão?

\section{Como a angústia nos impele a refletir?}

De fato, a angústia é um afeto que se desencadeia porque é impossível experienciar todos os objetos, seja porque não os conhecemos, seja porque estão proibidos, seja porque são desagradáveis. Em todos os casos, trata-se de um afeto que se desencadeia porque não podemos fazer a experiência da ubiquidade, o que quer dizer que é a mesma impossibilidade empírica que desencadeia a angústia e a lógica reflexiva da equivalência. Resta saber como se passa de uma à outra. $\mathrm{Na}$ realidade, para que a angústia exerça seu papel de sinal, é necessário identificar um objeto como idêntico àquele que encontramos antes, o que traduzimos pelo princípio de identidade: “A = A” (SALEM, 1987/1994, p.34). Não obstante, estando escrito desse modo, esse princípio não permite ainda desvelar toda sua lógica, é preciso também que sejamos capazes de substituir A por outros objetos julgados equivalentes. Por exemplo, uma poltrona é equivalente a uma cadeira com dois apoios para os braços, então, obtemos: "P $=\mathrm{C}+2 \mathrm{~A}$ ", ou um banquinho é equivalente a uma cadeira menos um encosto, e obtemos então: “B = C - E”. Ora, essa lógica de equivalência do princípio de identidade não é senão o processo psíquico do recalcamento. De fato, a impossibilidade empírica da ubiquidade conduz a desejar objetos inacessíveis cuja representação se torna angustiante, por mais que esteja recalcada. Entretanto, sem representação o afeto 
não pode mais se escoar sobre o objeto, posto que este não é mais identificável. O afeto vai, portanto, se animar de uma dinâmica que consiste em identificar outros objetos equivalentes àquele que está inacessível, e sobre os quais vai poder se escoar. Dito de outro modo, esse processo psíquico do recalcamento corresponde exatamente à lógica da equivalência do princípio de identidade.

Assim, o fato de não poder experienciar tudo engendra uma angústia cuja dinâmica afetiva consiste em incluir na sua consciência representações equivalentes àquela que foi recalcada no inconsciente, de sorte que é a dinâmica afetiva da inclusão que constitui o movimento da lógica de equivalência. Observemos, aliás, que a identificação não é própria da angústia, uma vez que onde identificamos objetos como sendo satisfatórios e sobre os quais a pulsão pode ser satisfeita, isso permite reconhecê-los quando se apresentem outra vez. Não obstante, evocamos mais as pulsões satisfatórias porque não propõem problema particular, ao contrário das pulsões que não podem ser realizadas. Por outro lado, embora Aristóteles tenha descrito as quatro lógicas clássicas, as duas lógicas reflexivas foram apresentadas de maneira precisa, sobretudo por Leibniz, que trabalhou muito sobre o princípio de identidade (LEIBNIZ, 1765/1990, p.179-191), em especial porque se interessava pela reflexividade da lógica. Da mesma maneira, ele trabalhou muito sobre o princípio da razão suficiente que vamos evocar em seguida, uma vez que ele mesmo é o autor dessa denominação. Assim, o que Leibniz descreveu observando o discurso reflexivo, Freud descreveu observando a clínica, a tal ponto que podemos nos perguntar que diferença existe entre a lógica reflexiva da equivalência e a dinâmica afetiva da inclusão.

\section{Que diferença existe entre a lógica reflexiva da equivalência e a dinâmica afetiva da inclusão?}

De fato, trata-se do mesmo movimento, apenas expresso de maneira diferente. Para colocá-lo em evidência, lembremos que os afetos são quantidades de energia que não podem sair do corpo senão escoando sobre os objetos. São os afetos que animam o corpo, movendo-o por meio de ações que permitem buscar os objetos. E são esses movimentos inscritos no espaço e no tempo que constituem as dinâmicas espacial e temporal dos afetos, dando lugar, dessa maneira, a comportamentos mais ou menos adaptados à busca de objetos. Entretanto, essas quantidades de energia que devem sair do corpo para escoar sobre os objetos, o fazem também por meio da voz e da escrita. E são essas sonoridades e esses escritos inscritos no espaço e no tempo que constituem as lógicas espacial e temporal da reflexão. Assim, as dinâmicas afetivas se exprimem seja por um comportamento, seja por um discurso, seja por ambos. Embora nossa hipótese epistemológica dos afetos reflexivos se veja confirmar pela observação clínica dos trabalhos de Golse (2006, p.256), segundo os quais os afetos são indissociáveis da voz. Para 
compreender as razões disso, vamos agora desenvolver a hipótese linguística que consiste em mostrar de que maneira as dinâmicas afetivas encontram sua expressão em nossa linguagem, seja oral ou escrita.

De fato, distinguindo os afetos das representações para cada destino pulsional, podemos pôr em destaque o fato de que os afetos constituem o movimento das lógicas, como acabamos de fazer para a dinâmica afetiva da inclusão e a lógica reflexiva da equivalência. Mas o fato de distinguir os afetos das representações também permite pôr em evidência o fato de que os afetos se exprimem por meio de sons ou de escritas que dão forma às representações às quais estão ligados, o que Saussure (1916/1998, p.99) chama respectivamente de imagem acústica e conceito, ou ainda o significante e o significado. O afeto está, portanto, ligado à sua representação, como o significante o está ao significado, embora a energia pulsional não se expresse apenas por meio de ações, mas também por palavras ou escritos que visem os objetos representados. É por isso que o fato de falar ou escrever permite liberar as energias pulsionais, o que chamamos na clínica de 'função catártica da palavra'. Resta a compreender como a dinâmica afetiva de inclusão se expressa no discurso.

Ela o faz de diversas maneiras, e evocaremos algumas. Em primeiro lugar, quando recalcamos uma representação, o afeto se encontra sozinho, isto é, o significante se encontra sem o significado, o que nos leva a exprimir uma palavra sem que a representação que de hábito lhe atribuímos lhe esteja associada.

Cometemos, então, um lapso (FREUD, 1915-17/2000, p.473), que é uma das manifestações do inconsciente. Enquanto isso, esse lapso não é expressão do recalcamento, mas apenas de seu fracasso, uma vez que exprimimos uma palavra no lugar de outra, ao passo que não o teríamos feito se o recalcamento tivesse sido bem-sucedido. De fato, quando o recalcamento é bem-sucedido, a dinâmica afetiva se vê sem representação, e vai então investir em outras que lhe são equivalentes, isto é, vai exprimir uma palavra substituindo-a por outras que terão o mesmo sentido, o que não é senão um aperfeiçoamento de definição. Dito de outro modo, a dinâmica afetiva da inclusão permite definir as palavras, estabelecendo equivalências entre elas, o que quase sempre se traduz em francês por “é”, ou, em matemática, pelo “=”. Observemos, além disso, que as palavras que empregamos são tomadas de empréstimo a alguém para designar representações que julgamos equivalentes às desse alguém, ainda que sempre tenhamos herdado as línguas naturais em função do espaço onde nos encontramos (SAUSSURE, 1916/1998, p.261).

Eis aí de que maneira a dinâmica afetiva da inclusão permite estabelecer equivalências entre as representações de cada palavra, o que permite defini-las sabendo de que estamos falando. Vejamos agora como o tempo nos impele a refletir. 


\section{COMO O TEMPO NOS IMPELE A REFLETIR?}

\section{Como o tempo afeta nossa representação dos objetos?}

Distinguimos a dimensão temporal da dimensão espacial para facilitar nosso estudo, mas as duas permanecem indissociáveis na realidade da experiência, mesmo se uma delas muitas vezes é suscetível de nos afetar mais do que a outra. Assim, a maneira como o tempo nos afeta está intimamente ligada à do espaço, embora possamos determinar o afeto temporal da reflexão partindo do afeto de espaço. Por exemplo, quando o objeto desejado é proibido, sua presença pode provocar angústia e engendrar o recalcamento da representação, como já vimos. Mas o próprio fato de que o objeto tenha podido estar presente sem que a pulsão fosse satisfeita pode também provocar frustração, uma vez que representa uma ocasião que não deu certo. A angústia e a frustração, portanto, estão ligadas, como Freud (1896/2005, p.115) já enfatizava, ainda mais porque se a interdição do objeto não for suficientemente ameaçadora para provocar a angústia, mas que seja bastante inibitória para impedir a satisfação pulsional, então a representação do objeto não é recalcada e, ao contrário, evidencia uma ocasião que falhou para satisfazer a pulsão, o que é frustrante. É por isso que o afeto temporal da reflexão é a frustração.

Mas o que é feito da energia afetiva ligada à representação de um objeto que não está mais à disposição? De fato, se o objeto desejado é proibido, desconhecido, inacessível, insatisfatório, ou não está mais à disposição, ou se simplesmente o objeto não existe, então a energia afetiva ligada à sua representação vai consistir em descobrir os meios que sejam suficientes para criá-la em função da imagem que se tenha dela, de modo que a falta do objeto seja compensada por sua criação. Por conseguinte, a dinâmica afetiva da frustração é a compensação, não tanto porque o objeto criado substituiu aquele que não existe, mas antes porque a quantidade de energia pulsional pode escoar pela busca dos recursos que bastem para criar o objeto, matiz que se torna evidente à luz da atividade artística. Pintar a mulher ideal numa tela permite satisfazer uma pulsão que é muito diferente daquela que se poderia ter sobre uma mulher real, o que mostra bem que a dinâmica afetiva se escoa mais pela criação do objeto do que pelo próprio objeto (FREUD, 1908/2004, p.33). Essa dinâmica afetiva da compensação é, portanto, o motor de uma pulsão que consiste em sublimar o objeto desejado, de maneira que a frustração é o afeto que desencadeia o destino pulsional da sublimação (FREUD, 1930/2006, p.266).

Assim, o fato de não poder experienciar a eternidade, isto é, o fato de não poder reter eternamente sua energia pulsional diante de um objeto proibido, desconhecido, ou fantasiado, engendra uma frustração cuja dinâmica afetiva consiste em compensar a falta do objeto encontrando os recursos para sublimá-lo. 
Eis aí de que maneira o tempo afeta nossa representação dos objetos; mas como esse processo psíquico pode constituir um dos motores de nossa reflexão?

\section{Como a frustração nos impele a refletir?}

A impossibilidade empírica da eternidade é também aquela que desencadeia a “lógica indutiva do princípio da razão suficiente, no sentido de que o fato de não poder experienciar eternamente o mesmo objeto nos impele a induzir as razões que bastem para determinar seu estado num instante determinado. Essa lógica indutiva do princípio da razão suficiente foi muito estudada por Leibniz (1765/1990, p.375-392), e se escreve da maneira seguinte: "pつq" ou "p $\longrightarrow q$ " (SALEM, 1987/1998, p.13). Esta escrita se lê “p implica q”, sendo “p” uma razão que basta para engendrar “q”. Expliquemos com precisão que esse princípio é reflexivo (LEIBNIZ, 1765/1990, § 4, p.40), uma vez que exige fazer girar em sua mente diversas representações para ver qual objeto implica o outro, seja num sentido ou em outro, o que pressupõe, ainda, poder destacar os objetos idênticos e aqueles que são equivalentes entre si. É por isso que, com frequência, o princípio da razão suficiente se articula com o princípio de identidade e ambos engendram lógicas reflexivas, como Leibniz explica. Essa articulação entre os dois princípios confirma o caráter indissociável que une a dimensão espacial e a dimensão temporal da experiência. Resta compreender como a dinâmica afetiva de compensação pode constituir o movimento da lógica indutiva do princípio da razão suficiente.

Na realidade, a lógica indutiva do princípio da razão suficiente é subtendida pela dinâmica afetiva da compensação, porque o fato de não poder reter eternamente sua energia pulsional diante de um objeto proibido, desencadeia uma frustração que nos impele a compensar a falta do objeto encontrando as razões suficientes para sublimá-la, isto é, que a frustração nos conduz a encontrar os recursos que permitem criar o objeto tal como ele é fantasiado ou tal como é representado, conforme o atestam as criações artísticas e científicas. É, portanto, a impossibilidade empírica da eternidade que desencadeia um afeto de frustração cuja dinâmica afetiva constitui o movimento da lógica indutiva do princípio da razão suficiente. Assim, quando se exprime pelo comportamento, a frustração engendra o destino pulsional da sublimação, e quando se exprime pelo discurso, engendra a lógica indutiva do princípio da razão suficiente, de modo que analisando o comportamento e o discurso, podemos encontrar a mesma dinâmica afetiva, a da compensação. Podemos então perguntar-nos o que diferencia a lógica indutiva. 


\section{Que diferença existe entre a lógica reflexiva da indução e a dinâmica fetiva da compensação?}

A diferença entre as duas resulta apenas do fato de que uma é o motor da outra, no sentido de que a dinâmica afetiva da compensação dá movimento à lógica indutiva quando esta se exprime pelo discurso. Na realidade, as dinâmicas afetivas e suas lógicas são, elas mesmas, constitutivas das línguas naturais, como nossa hipótese linguística o confirmou mais acima pela inclusão. Nessa perspectiva, pareceria coerente que se confirmasse também para a dinâmica afetiva da compensação. De fato, encontramos essa dinâmica na linguagem, em especial porque todos os significantes que utilizamos se inscrevem numa temporalidade (SAUSSURE, 1916/1998, p.103) que indica a ordem na qual se encadeiam. Essa temporalidade se manifesta, além disso, pela conjugação dos verbos e permite exprimir qual coisa implica tal outra, isto é, que os tempos utilizados para cada frase se compensam entre si conforme determinada concordância que permite exprimir qual coisa é induzida por tal outra. A dinâmica afetiva da compensação pode, dessa maneira, exprimir-se pela criação de neologismo para designar uma realidade que ainda não era, de modo que a criação de um significante compensa a falta de um significado.

Esses exemplos demonstram que a dinâmica afetiva de compensação se exprime de maneira linguística, possibilitando, então, a expressão de uma reflexão indutiva.

\section{CONCLUSÃO}

Em suma, nossa hipótese epistemológica fica bem confirmada, uma vez que os afetos efetivamente constituem o motor das reflexões, o que demonstramos pondo em evidência o fato de que a impossibilidade de realizar uma experiência engendra um afeto cuja dinâmica se exprime por um destino pulsional ou por uma lógica reflexiva conforme se trate de um comportamento ou de um discurso. Assim, o fato de não poder experienciar tudo engendra uma angústia cuja dinâmica consiste em incluir representações equivalentes às que tinham sido recalcadas, o que se exprime pelo destino pulsional de recalcamento ou pela lógica reflexiva da equivalência. Da mesma maneira que o fato de não poder experienciar o objeto desejado engendra uma frustração cuja dinâmica consiste em compensar a falta do objeto induzindo as razões que bastem para sublimá-lo, o que se exprime pelo destino pulsional da sublimação ou pela lógica reflexiva da indução. Vimos, por outro lado, que nossa hipótese linguística foi, ela também, confirmada, uma vez que as dinâmicas afetivas da inclusão e da compensação são inerentes às línguas naturais, o que permite exprimir as lógicas de equivalência e de indução. 
Por fim, essas hipóteses que desenvolvemos mais em outro lugar (TOUSSEUL, 2010) invertem a ideia tradicional segundo a qual uma boa reflexão deveria ser isenta de afetos, porque, ao contrário, eles são os motores desta e determinam, assim, as normas psíquicas do comportamento e do pensamento.

Recebido em 14/4/2011. Aprovado em 25/6/2011.

\section{REFERÊNCIAS}

ARISTÓTELES. (1991) Métaphysique. Trad. J. Tricot. Tome I, livre IV, Ch. 4, 1006a5-15. Paris: Vrin.

ASSOUN, P.L. (2006) Leçons psychanalytiques sur l'angoisse. Paris: Anthropos. FREUD, S. (2005) Oeuvres complètes. Trad. sob a dir. de J. Laplanche. Paris: PUF.

(1896) “L’hérédité et l’étiologie des névroses”, v.III.

(1911) “Formulations sur les deux principes de l'advenir psychique”, v.XI.

(1915-17/2000) “Leçons d’introduction à la psychanalyse”, v.XIV.

(1930/2006)"Le malaise dans la culture”, v.XVIII.

(1908/2004) “La morale sexuelle 'civilisée’ et la maladie nerveuse des temps modernes". In: . La vie sexuelle. Trad. D. Berger. Paris: PUF.

(1915/2002) Métapsychologie. Trad. J. Laplanche \& J. B. Pontalis. Paris: Gallimard.

(1926/2002) Inhibition, symptôme et angoisse. Trad. J. \& R. Doron. Paris: PUF.

GÖDEL, K. (1931) Über formal unentscheidbare Sätze der Principia mathematica und verwandter Systems I. Monatshefte für Mathematik und Physik, v.38, p.173-198.

GOLSE, B., (2006) L'être-bébé. Paris: PUF.

KANT, E. (1798/2002) Anthropologie du point de vue pragmatique. Trad. M. Foucault. Paris: Vrin.

LARGEAULT, J. (1993-1998.) La logique. Paris: PUF.

LE GUEN, C. (1992-1997) Le refoulement. Paris: PUF.

LEIBNIZ, G. W. (1765-1990) Nouveaux essais sur l'entendement humain. Paris: Flammarion.

SALEM, J. (1987-1998) Introduction à la logique formelle et symbolique. Paris: Nathan.

SAUSSURE, F. (1916-1998) Cours de linguistique générale. Paris, Payot.

TOUSSEUL, S. (2006) Les limites de l'expérience comme principe fondamentaux de la science. Essai sur les relations empirique, logique, et métaphysique. Les cahiers de l’Ecole, n.6, p.38-57. Disponível em: http:// www.cahiers-ed.org/ftp/cahiers6/C6_tousseul.pdf

(2009) L'affect et la raison. Recherches en Psychanalyse, n.7. Disponível em: http://recherchespsychanalyse.revues.org/index233.html

Pedro Henrique Bernardes Rondon

phbrondon@gmail.com 